\title{
Sleep in Intensive Care Unit Patients
}

\author{
Jin Park ${ }^{1,2}$ \\ Departments of ${ }^{1}$ Neurology and ${ }^{2}$ Critical Care Medicine, Seoul Hospital, Ewha Womans University College of Medicine, Seoul, Korea
}

\section{중환자실 환자의 수면}

박 진 ${ }^{1,2}$

이대서울병원 ${ }^{1}$ 신경과, ${ }^{2}$ 응급중환자진료과

$\begin{array}{ll}\text { Received } & \text { July 26, 2021 } \\ \text { Revised } & \text { August 4, 2021 } \\ \text { Accepted } & \text { August 6, 2021 }\end{array}$

Address for correspondence Jin Park, MD

Departments of Neurology and Critical Care Medicine,

Seoul Hospital,

Ewha Womans University

College of Medicine,

260 Gonghangdae-ro,

Gangseo-gu, Seoul 07804, Korea

Tel: +82-2-6986-4256

Fax: +82-2-6986-7000

E-mail: j201703@gmail.com
Sleep disturbances are common among patients admitted to the intensive care unit (ICU); however, these issues tend to receive less attention because critical care is prioritized in seriously ill patients. Recent studies have reported that sleep disturbances in patients admitted to the ICU are associated with delirium, weakened immunity, long-term cognitive decline, and persistent sleep disorders. Sleep disturbances in the ICU are attributable to the disease per se and also to the ICU environment that is not conducive to good sleep. Continuous exposure to light and noise are major environmental risk factors that disrupt the circadian rhythm and interfere with deep sleep. Sleep analysis using polysomnography in patients admitted to the ICU typically reveals increase in sleep latency, sleep fragmentation, and decreased stage N3 and rapid eye movement sleep, which are associated with poor prognosis even in patients with severe neurological conditions, including traumatic brain injury and intracranial hemorrhage. Polysomnography is the gold standard for objective evaluation of sleep; however, its applicability is limited in ICU settings, and novel methods such as continuous electroencephalographic spectral analysis and actigraphy have recently been proposed in clinical practice. Efforts to reduce nighttime light and noise (which are modifiable environmental factors) can improve sleep quality. In this article, the author reviews the studies that discuss characteristics of sleep disturbances, the associated risk factors and their correlation with prognosis among patients admitted to the ICU, as well as possible strategies to improve sleep quality in this patient population.

J Sleep Med 2021;18(2):66-71

Keywords: Sleep; Intensive care unit; Circadian rhythm.
서 론

인간의 일생 중 약 $1 / 3$ 을 차지하는 수면은 건강한 일상을 유지하기 위한 필수적 생리 현상이며, 현대에 이르러 수많은 질환과의 연관성이 밝혀져 그 중요성이 더욱 주목받고 있 다. ${ }^{1,2}$ 중환자실에 입원한 환자에서도 예외가 아니지만 중환 자의 수면에 대해서는 최근까지도 연구대상으로 많이 다뤄 지지 않았다. 중환자 치료는 가장 우선순위인 급성 중증의 질환에 대한 처치를 중심으로 집중적인 감시와 다양한 처치 를 긴박하게 시행하기 때문에 상대적으로 중환자의 정상적

This is an Open Access article distributed under the terms of the Creative Commons Attribution Non-Commercial License (https://creativecommons.org/licenses/by-nc/4.0) which permits unrestricted non-commercial use, distribution, and reproduction in any medium, provided the original work is properly cited.
인 수면에 대한 관심은 적었다. 또한 질환 자체의 영향뿐만 아니라 치료에 필수적인 일련의 과정이 지속적인 자극으로 환자의 수면을 방해하게 된다. 의식이 있는 환자에서 통증, 달라진 환경과 질환에 대한 불안, 불면 등을 비롯하여 중환 자실의 환경적 요인인 빛, 소음, 악취, 신체 움직임의 제한, 일반적 간호처치까지 정상적인 수면의 방해요인으로 작용할 수 있다. ${ }^{3}$ 또한 수면장애 진단의 표준 검사인 수면다원검사 를 중환자실에서 시행하기 어렵고, 깊은 진정을 시행하거나, 뇌손상으로 의식이 없는 환자에서 수면의 정의에 대한 논의 가 충분하지 않은 점 등 중환자실 환자의 수면에 접근하는 첫 단계인 수면 상태의 평가부터 쉽지 않다.

그럼에도 불구하고 중환자실 환자에서 수면 문제가 단기 적 예후, 섬망을 비롯하여 면역체계와 감염, 기계환기 기간의 
증가, 인지기능 저하, ${ }^{4-6}$ 그리고 중환자실을 벗어난 이후 지속 적인 수면 및 인지기능까지,8 장기적인 삶의 질과 연관성이 있다는 보고들이 나오고 있다. 중환자에서 수면의 중요성에 대한 근거가 쌓이고 중환자의 예후 향상을 위한 조절가능한 요인으로 인식의 전환이 되면서, 수면 개선을 위한 적극적인 노력에 대한 공감대가 형성되었다. 이를 반영하여 2018년 미 국 중환자의학회(Society of Critical Care Medicine, SCCM) 에서 중환자실의 통증, 진정, 섬망 지침(pain, agitation, $\mathrm{de}^{-}$ lirium guideline)을 개정하며 수면에 대한 내용이 추가되었 다(pain, agitation/sedation, delirium, immobility, and sleep guideline). ${ }^{3}$ 본 종설에서 중환자실 환자의 수면에 대해 최근 의 연구들과 지침을 바탕으로 살펴보도록 하겠다.

\section{본 론}

\section{중환자실 환자의 수면 문제}

중환자실에서 발생하는 수면 문제는 수면 부족, 수면 방해 및 수면 구조의 이상 등 다양하게 나타나며 여러 연구들에서 약 25\%에서 $70 \%$ 까지 매우 흔하게 보고되고 있다. ${ }^{8-10}$ 환자의 자가보고에 의한 수면을 방해하는 요소는 움직임 제한, 통증, 불안, 마스크 착용 등 환자의 주관적 요인뿐만 아니라, 소음, 빛 등 환경적 요인에 이르기까지 다양하다. ${ }^{11}$

이런 수면 문제는 중환자실 치료 이후 지속적으로 환자의 예후에도 영향을 준다. 중환자실 환자의 수면장애는 약 $50 \%$ 의 환자에서 퇴원 1 주 후에도 보고되고, 약 6 개월 후에도 $1 / 3$ 에서 중등도 이상의 수면 문제가 지속되며, 장기적인 삶의 질, 정신적 회복, 재활치료의 어려움을 겪게 한다. ${ }^{12}$

\section{중환자실 수면 문제의 위험요인}

환자 관련 요인은 원인 질환의 종류 및 중등도, 통증, 스트 레스/불안, 이전의 수면장애나 정신과적 병력 등이 가장 주 요한 요인이다. ${ }^{13,14}$ 중환자의 수면장애의 위험요인으로 환자, 환경적 요인 모두 중요하지만, 조절하기 쉽지 않은 환자 관 련 요인보다 조절 대상으로 더 의미를 갖는 것은 환경적 요 인이다.

환경적 요인 중 가장 대표적인 것은 빛과 소음이다. 중환 자실에서 시행한 정상인의 수면다원검사에서 알 수 있듯이 환경요인 자체로 인해 잦은 각성과 깊은 수면 방해를 일으 킨다. ${ }^{15}$ 중환자실 1 인실이 일반적인 미국에서도 평균적인 중 환자실 내 소음 수준이 55-65 dB이며, 주간 $45 \mathrm{~dB}$, 야간 35 $\mathrm{dB}$ 이내의 최고 소음 기준을 충족하지 못하는 경우가 많다. ${ }^{16}$ $80 \mathrm{~dB}$ 이상의 소음은 각성을 일으키며, 약 $20 \%$ 정도의 수면 중 각성과 소음이 연관되어 있다. 17,18 빛은 야간 중 100-500 lux 정도만 되어도 melatonin 분비와 일주기리듬(circadian rhythm)을 변화시킬 수 있다. ${ }^{19}$ 그외에도 환자의 치료를 위해 필수적인 기계환기, 간호활동-혈압측정, 검체 채취, $x$-ray 촬영, 가래 흡인, 자세변경 등도 수면을 방해할 수 있다.

중환자실 환자의 치료에 있어 필수적인 진통, 진정제도 수 면에 영향을 줄 수 있다. 진정제로 많이 사용되는 benzodiazepine은 수면잠복기(sleep latency)를 감소시켜 수면을 유도 하는 데 널리 사용되지만, 서파수면 및 rapid eye movement (REM) 수면을 감소시켜 결과적으로 수면의 질이 나빠질 수 있다. 기계환기를 적용하는 환자에서 많이 사용되는 propofol 역시 서파수면을 억제하고, 중환자실 진통제의 대표적 약물인 아편계 진통제는 REM 수면을 변화시킨다고 알려져 있다. 중환자실에서 흔히 사용하는 승압제나 강심제는 아드 레날린성 효과로 수면에 영향을 줄 수 있으며, 베타차단제는 불면증을 유발하거나 REM 수면을 억제하고, quinolone계 항생제는 $\gamma$-aminobutyric acid (GABA)-A 수용체 억제를 통해 수면을 방해할 수 있다. ${ }^{20,21}$

\section{중환자실 환자의 수면 문제 특징}

중환자실 환자의 수면 문제 특징은 다음과 같다. 수면다원 검사에서 증가한 수면잠복기, 수면 중 잦은 각성으로 인한 수면분절(sleep fragmentation), N2 수면 단계(non-REM sleep stage 2)의 증가, 깊은 수면(stage N3) 감소 또는 부재, $\mathrm{REM}$ 수면의 감소 또는 부재이다. ${ }^{14,22-24}$ 정상인에 비해 총 수 면시간은 크게 차이가 없으나 약 50\%가 낮 동안 이뤄지는 주 간수면(daytime sleep)의 증가를 보이며 일주기의 손상(disrupted circadian rhythm) 역시 특징적이다. ${ }^{25-27}$

수면평가를 위해 수면다원검사를 중환자에서 시행하였을 때 N2 수면 단계로 판독하는 기준인 수면방추파(sleep spin$\mathrm{dle}$ )나 $\mathrm{K}$ 복합체(K complex) 등이 20\%-44\%에서 관찰되지 않았다. $16,28,29$ 중환자실 환자의 질환과 급성 병적 상태에 의한 생리학적 변화뿐만 아니라 진정제, 승압제 등 수면에 영향을 주는 약물의 효과도 감안해야 한다.

\section{중환자실 수면에 영향을 주는 생리학적인 변화}

급성기의 중환자실 환자에서는 GABA성 신경세포와 콜린 성 신경(cholinergic neuron) 활성이 감소하며, 도파민 전달은 증가하여 각성의 불균형이 생긴다. 스트레스 상황에서 코티 솔(cortisol)이 증가하며, 전신의 염증반응은 연쇄적으로 다른 호르몬에도 영향을 미친다. 이와 함께 지속적인 빛 등 환경적 요인에 의해 수면에 중요한 멜라토닌(melatonin) 분비에 이 상이 생긴다. ${ }^{25}$

중환자실 환자의 수면 부족은 면역체계를 저하시켜 감염 
의 발생을 높일 수 있으며, 다양한 호르몬의 변화를 초래한 다. 코티솔, 노르에피네프린(norepinephrine), 갑상선 호르몬 이 증가하며, 성장호르몬이 감소하고, 인슐린 저항성이 증가 한다. ${ }^{30}$ 또한 근육의 피로가 증가하여 특히 호흡근의 기능 저 하가 생긴다. 신경인지기능에도 영향을 줘서 섬망의 발생을 증가시키고, 기억력 저하, 주의력 감소 등의 인지기능 저하를 일으킨다. ${ }^{22}$

일주기리듬의 이상도 중환자실 환자의 생리적 변화를 일 으킨다. 정상인에서 수면은 약 20\%-30\% 정도의 깊은 수면 과 20\%-25\%의 REM 수면으로 이뤄져 있지만, 중환자는 이 와 다른 수면 구조를 보여준다. 중환자실 환자에서 수면다원 검사를 시행한 한 연구에서 N1, N2 수면은 각각 약 $20 \%$, $70 \%$ 였으나, 깊은 수면과 REM 수면은 약 5\% 미만이거나 관 찰되지 않았다. ${ }^{31}$ 정상적으로 $\mathrm{GABA}$ 활성이 깊은 수면 동안 증가하고, 도파민 활성은 수면을 감소시키며 각성을 유도한 다. 빛의 감소에 따라 밤 9 시경부터 멜라토닌 분비가 시작되 어 새벽 3시경 최고조에 도달하고, 코티솔은 아침에 분비되어 오후가 되며 점차 분비가 감소한다. 이런 일주기리듬에 따라 심혈관 및 체온 등 중요한 생체주기가 결정된다. 그러나 중 환자실은 외부 변화를 차단한 인공적 환경으로 빛에 의한 일 주기리듬을 방해하여 정상적 수면 패턴과 다른 양상을 보이 게 된다. 추가로 중증 질환에 의해 목표체온유지치료로 체온 을 조절하거나, 염증 및 감염에 의한 열, 부신기능부전 등에 의해 체온의 일주기 변화 조절 기능도 제한될 수 있다. ${ }^{24}$

\section{중환자실 환자의 수면 문제와 예후: 섬망, 인지기능 저하, 면역반응 저하}

중환자실 환자의 20\%-80\%에서 경험하는 섬망은 사망률, 중환자실 재원기간을 증가시키고, 장기적인 인지장애와 연 관성이 밝혀져 중환자 치료의 관심질환이다. 수면장애는 섬 망 발생의 위험인자이며, 수면 개선이 섬망 예방에 중요한 치료 항목 중 하나로 수면과 섬망 사이에 밀접한 연관성이 있 다. ${ }^{32,33}$ 뇌손상이 없이 섬망이 발생한 중환자에서 뇌파상 $\mathrm{K}-$ 복합체와 수면방추체 소실이 심한 뇌병증 및 높은 사망률과 의 연관성을 보여주기도 하였다. ${ }^{34}$ 수면을 개선하는 다양한 접근의 노력으로 섬망의 발생과 인지기능의 개선을 보여주 는 보고는 수면 개선이 중환자의 예후에도 영향을 줄 수 있다 는 것을 시사한다. ${ }^{35}$ 인지기능 저하는 중환자실 퇴원 이후의 삶의 질 저하에 매우 중요한 요소이다. 중환자실에 입원했던 환자는 동일 연령대의 인구에 비해 인지기능 저하가 나타나 며, 특히 섬망이 있는 환자에서 더욱 높게 나타난다. ${ }^{7}$

면역 반응과 수면장애와의 연관성은 임상에서 근거가 부 족하지만, 생리적 항상성을 유지하기 위해 호르몬과 사이토 카인(cytokine)을 조절하는 수면의 생리적 역할과 소규모 동 물 연구 등에서 연관성을 시사하고 있다. 수면시간이 감소할 수록 기생충 감염이 증가한다는 연구도 있다. ${ }^{36}$ 수면 부족 상 태에서 항체 생산하는 림프구 분열의 억제, 항원을 인식하는 데 관여하는 human leukocyte antigen-DR 발현의 감소, $\mathrm{CD} 4+, \mathrm{CD} 8+\mathrm{T}$ 세포의 변화 등이 감염원에 대한 정상적 면역 반응이 이뤄지지 않게 만든다. 37,38

뇌손상이 있거나 혼수상태의 환자는 중환자실 수면 연구 에서 제외되는 경우가 많지만 몇몇 중증 신경계질환 환자를 대상으로 한 연구에서도 수면과의 연관성을 찾아볼 수 있다. 중증 외상성뇌손상 환자의 지속뇌파검사에서 N2 수면의 부 재는 불량한 예후의 독립적 위험인자였다. ${ }^{39}$ 뇌내출혈 환자에 서도 N2 수면이 확인되는 환자는 퇴원 후 양호한 기능적 예 후를 시사하는 예측인자였다. ${ }^{40}$ 신경계 중환자실에 입원한 환 자의 거의 $90 \%$ 가 중환자실에서의 기억을 떠올리지 못함에 도 불구하고 중환자실 치료 이후에도 지속적인 수면장애를 호소한다. ${ }^{41}$ 이것은 의식이 명료하지 않은 뇌손상 환자에서 도 수면에 대한 관심이 필요함을 시사한다고 할 수 있다.

\section{수면 평가 방법의 종류와 한계}

수면 평가는 뇌파, 안전도, 근전도, 심전도 등으로 수면 단 계를 분석하는 수면다원검사가 가장 정확한 방법이다. 그러 나 수면다원검사는 여러 장비가 필요하고, 전기신경생리검 사에 잡파가 생기기 쉬운 중환자실 환경에서 실제 시행하기 는 쉽지 않다. ${ }^{28}$

뇌파의 스펙트럼분석(spectral analysis)은 시각적 점수 판 정에 비해 연구자 내, 연구자 간 분석의 신뢰도가 높아 비교 적 정확한 방법으로 제시되고 있으나 실제 임상에서 적용이 쉽지 않다는 한계가 있다. ${ }^{28}$ 활동기록기(actigraphy)는 적용이 쉽고, 수면다원검사와 유의한 연관성을 수면장애 환자에 대 한 연구에서 입증하여 최근에 주목받고 있다. 중환자실 환자 에서 적용은 아직 근거가 충분하지 않지만 검사가 쉽다는 장 점이 있어 향후 적용해볼 수 있겠다. ${ }^{42}$ 수면에 대해 환자에게 직접 설문조사하는 방법도 있으며, 대표적으로 중환자실 환 자를 대상으로 검증된 Richards-Campbell Sleep Questionnaire가 알려져 있다. 그러나 환자가 의식이 없는 경우 적용 하기 어렵다는 단점이 있다. 신경학적 손상이 있는 환자에서 수면의 측정은 더욱 쉽지 않은 문제이다. 한 연구에서 지속 뇌파 측정을 통해 수면을 분석하였을 때 뇌손상이 심한 환자 일수록 서파 또는 이상뇌파 소견으로 수면 단계 평가를 하기 어려웠고, 약 $35 \%$ 에서 수면 단계 측정이 가능하였다. ${ }^{43}$ 이러 한 환자에서 수면에 대한 연구 지침이 필요할 것으로 보인다. 


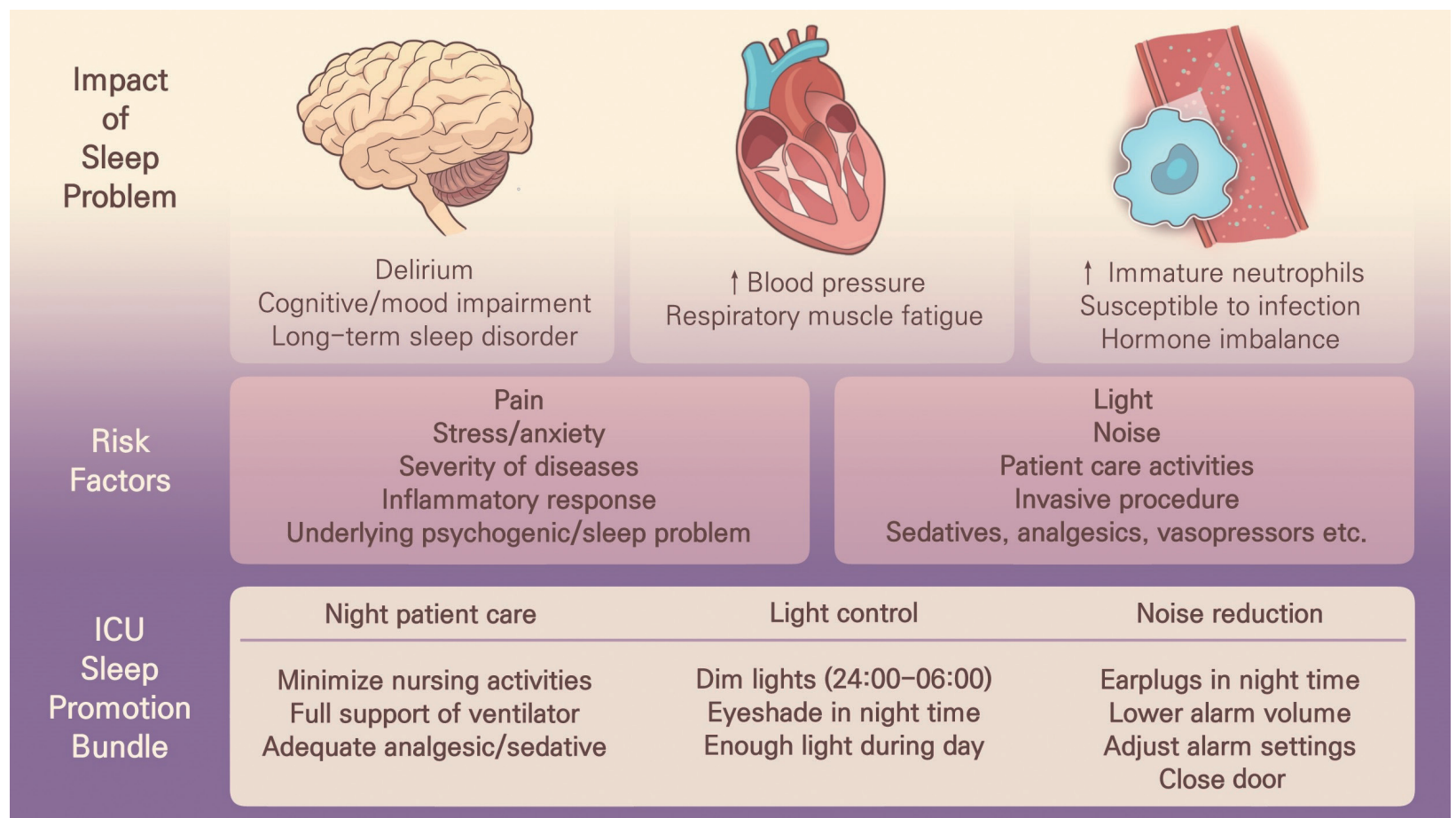

Figure 1. Sleep problems in ICU patients-impact, risk factors, and promotion bundle. ICU, intensive care unit.

\section{중환자실 수면 개선을 위한 노력}

환자 측 원인을 교정하기 어려우므로 환경적 요인 조절을 우선 목표로 하는 것이 적절한 전략이다. 건강한 사람도 중 환자실 환경에서 수면장애가 발생한다는 연구로 미루어 보 아 환경 개선의 효과를 추정할 수 있으므로 중환자실의 야간 환경을 수면에 적합하도록 바꾸는 데 관심과 노력이 필요하 다. ${ }^{15}$ 야간 시간에 반복적인 간호 활동의 최소화, 오전 6시 이 전의 채혈 및 영상 검사 시간대 변경 등 다양한 환경적 중재 를 bundle로 만들어 섬망 감소를 보고한 연구도 있다. ${ }^{4}$ 중환 자실 환자의 수면 문제와 위험요인, 개선을 위한 노력을 Fig. 1 에 정리하였다.

빛은 100-500 lux 정도만 되어도 멜라토닌 분비와 일주기 리듬을 변화시키므로 야간에 전체 중환자실의 중앙 광원은 소등하고, 환자 주변에 불빛을 최소화해야 한다. ${ }^{45}$ 반대로 낮 에는 빛이 충분히 들어올 수 있도록 전체 중환자실의 채광을 고려해야 한다. 간단하게 야간 시간에 귀마개와 수면 안대를 사용하여 수면의 질 향상에 도움을 줬다는 보고가 있으며 이 를 임상에서 적용할 수 있다. 46,47

약물적 방법은 다양한 약물에 대한 연구가 있으나 뚜렷하 게 예후 개선을 보여 권고하는 약물은 아직까지 없다. 멜라 토닌은 수면 유도 효과에 대해 상반된 연구들로 근거가 약하 여 지침에서 추천하지는 않으나 특별하게 위험한 부작용이 없어 수면 유도를 위해 사용해 볼 수 있다..$^{48}$

최근에 널리 사용되는 dexmedetomidine은 선택적 $\alpha 2$-아
드레날린성 수용체 작용제로 N2 수면을 늘려 정상 수면과 유사한 진정을 유도하고, 일주기리듬을 보존하며, 섬망을 치 료하는 효과가 있다. ${ }^{49,50}$ 비용 부담이 크고 대규모 연구의 근 거가 충분하지 않아 수면 유도만을 위해서 사용하는 것은 권 고되지 않으나, benzodiazepine의 사용을 줄일 수 있다는 장 점이 있어 추가 연구가 필요하다. ${ }^{22}$

\section{결 론}

중환자실 환자의 수면 문제는 흔하게 발생하지만 임상적 으로 주목받지 못했다. 그러나 수면 문제가 인지기능 저하, 섬망 발생, 면역 저하 등 중환자실 환자의 단기 예후뿐만 아 니라 중환자실 이후 삶의 질 등 장기 예후와 연관성이 있다 는 사실이 밝혀지고 있다. 중환자실에서 수면의 질을 적절히 유지하기 위해 수면 상태를 감시해야 하며, 활동기록기, 뇌 파 스펙트럼분석 등 새로운 방법이 제시되고 있어 근거가 충 분히 쌓이면 임상에서 활용해 볼 수 있을 것으로 기대된다. 수면 환경의 개선을 위해 특히 야간 시간에 빛, 소음을 가능 한 차단해야 하며, 필요한 경우 약물적 보조치료를 고려해볼 수 있다.

\section{Conflicts of Interest}

The author has no potential conflicts of interest to disclose. 


\section{ORCID iD}

Jin Park https://orcid.org/0000-0002-4597-6344

\section{Funding Statement}

None.

\section{Acknowledgments}

I am very grateful to Uida for the illustration.

\section{REFERENCES}

1. Newman AB, Nieto FJ, Guidry U, et al. Relation of sleep-disordered breathing to cardiovascular disease risk factors: the Sleep Heart Health Study. Am J Epidemiol 2001;154:50-59. https://doi.org/10.1093/aje/ 154.1.50.

2. Luyster FS, Strollo PJ Jr, Zee PC, Walsh JK. Sleep: a health imperative. Sleep 2012;35:727-734. https://doi.org/10.5665/sleep.1846.

3. Devlin JW, Skrobik Y, Gélinas C, et al. Clinical practice guidelines for the prevention and management of pain, agitation/sedation, delirium, immobility, and sleep disruption in adult patients in the ICU. Crit Care Med 2018;46:e825-e873. https://doi.org/10.1097/CCM.0000000000003299.

4. Boesen HC, Andersen JH, Bendtsen AO, Jennum PJ. Sleep and delirium in unsedated patients in the intensive care unit. Acta Anaesthesiol Scand 2016;60:59-68. https://doi.org/10.1111/aas.12582.

5. Bryant PA, Trinder J, Curtis N. Sick and tired: does sleep have a vital role in the immune system? Nat Rev Immunol 2004;4:457-467. https:// doi.org/10.1038/nri1369.

6. Helton MC, Gordon SH, Nunnery SL. The correlation between sleep deprivation and the intensive care unit syndrome. Heart Lung 1980;9: 464-468.

7. Pandharipande PP, Girard TD, Jackson JC, et al. Long-term cognitive impairment after critical illness. N Engl J Med 2013;369:1306-1316. https://doi.org/10.1056/NEJMoa1301372.

8. Altman MT, Knauert MP, Pisani MA. Sleep disturbance after hospitalization and critical illness: a systematic review. Ann Am Thorac Soc 2017;14:1457-1468. https://doi.org/10.1513/AnnalsATS.201702-148SR.

9. Freedman NS, Kotzer N, Schwab RJ. Patient perception of sleep quality and etiology of sleep disruption in the intensive care unit. Am J Respir Crit Care Med 1999;159:1155-1162. https://doi.org/10.1164/ajrccm. 159.4.9806141.

10. Orwelius L, Nordlund A, Nordlund P, Edéll-Gustafsson U, Sjöberg F. Prevalence of sleep disturbances and long-term reduced health-related quality of life after critical care: a prospective multicenter cohort study. Crit Care 2008;12:R97. https://doi.org/10.1186/cc6973.

11. Jones J, Hoggart B, Withey J, Donaghue K, Ellis BW. What the patients say: a study of reactions to an intensive care unit. Intensive Care Med 1979;5:89-92. https://doi.org/10.1007/BF01686054.

12. McKinley S, Aitken LM, Alison JA, et al. Sleep and other factors associated with mental health and psychological distress after intensive care for critical illness. Intensive Care Med 2012;38:627-633. https:// doi.org/10.1007/s00134-012-2477-4.

13. Bihari S, Doug McEvoy R, Matheson E, Kim S, Woodman RJ, Bersten AD. Factors affecting sleep quality of patients in intensive care unit. $J$ Clin Sleep Med 2012;8:301-307. https://doi.org/10.5664/jcsm.1920.

14. Knauert MP, Yaggi HK, Redeker NS, Murphy TE, Araujo KL, Pisani MA. Feasibility study of unattended polysomnography in medical intensive care unit patients. Heart Lung 2014;43:445-452. https://doi. org/10.1016/j.hrtlng.2014.06.049.

15. Gabor JY, Cooper AB, Crombach SA, et al. Contribution of the intensive care unit environment to sleep disruption in mechanically ventilated patients and healthy subjects. Am J Respir Crit Care Med 2003; 167:708-715. https://doi.org/10.1164/rccm.2201090.

16. Freedman NS, Gazendam J, Levan L, Pack AI, Schwab RJ. Abnormal sleep/wake cycles and the effect of environmental noise on sleep dis- ruption in the intensive care unit. Am J Respir Crit Care Med 2001;163: 451-457. https://doi.org/10.1164/ajrccm.163.2.9912128.

17. Aaron JN, Carlisle CC, Carskadon MA, Meyer TJ, Hill NS, Millman RP. Environmental noise as a cause of sleep disruption in an intermediate respiratory care unit. Sleep 1996;19:707-710. https://doi.org/10.1093/ sleep/19.9.707.

18. Cabello B, Thille AW, Drouot X, et al. Sleep quality in mechanically ventilated patients: comparison of three ventilatory modes. Crit Care Med 2008;36:1749-1755. https://doi.org/10.1097/CCM.0b013e3181743f41.

19. Weinhouse GL, Schwab RJ. Sleep in the critically ill patient. Sleep 2006; 29:707-716. https://doi.org/10.1093/sleep/29.5.707.

20. Bourne RS, Mills GH. Sleep disruption in critically ill patients--pharmacological considerations. Anaesthesia 2004;59:374-384. https://doi. org/10.1111/j.1365-2044.2004.03664.x.

21. Unseld E, Ziegler G, Gemeinhardt A, Janssen U, Klotz U. Possible interaction of fluoroquinolones with the benzodiazepine-GABAA-receptor complex. Br J Clin Pharmacol 1990;30:63-70. https://doi.org/10.1111/ j.1365-2125.1990.tb03744.x.

22. Pisani MA, Friese RS, Gehlbach BK, Schwab RJ, Weinhouse GL, Jones SF. Sleep in the intensive care unit. Am J Respir Crit Care Med 2015; 191:731-738. https://doi.org/10.1164/rccm.201411-2099CI.

23. Hardin KA, Seyal M, Stewart T, Bonekat HW. Sleep in critically ill chemically paralyzed patients requiring mechanical ventilation. Chest 2006;129:1468-1477. https://doi.org/10.1378/chest.129.6.1468.

24. Gehlbach BK, Chapotot F, Leproult R, et al. Temporal disorganization of circadian rhythmicity and sleep-wake regulation in mechanically ventilated patients receiving continuous intravenous sedation. Sleep 2012;35:1105-1114. https://doi.org/10.5665/sleep.1998.

25. Daou M, Telias I, Younes M, Brochard L, Wilcox ME. Abnormal sleep, circadian rhythm disruption, and delirium in the ICU: are they related? Front Neurol 2020;11:549908. https://doi.org/10.3389/fneur.2020.549908.

26. Parthasarathy S, Tobin MJ. Sleep in the intensive care unit. Intensive Care Med 2004;30:197-206. https://doi.org/10.1007/s00134-003-2030-6.

27. Weinhouse GL, Schwab RJ, Watson PL, et al. Bench-to-bedside review: delirium in ICU patients - importance of sleep deprivation. Crit Care 2009;13:234. https://doi.org/10.1186/cc8131.

28. Ambrogio C, Koebnick J, Quan SF, Ranieri M, Parthasarathy S. Assessment of sleep in ventilator-supported critically III patients. Sleep 2008;31:1559-1568. https://doi.org/10.1093/sleep/31.11.1559.

29. Cooper AB, Thornley KS, Young GB, Slutsky AS, Stewart TE, Hanly PJ. Sleep in critically ill patients requiring mechanical ventilation. Chest 2000;117:809-818. https://doi.org/10.1378/chest.117.3.809.

30. Schmid SM, Hallschmid M, Jauch-Chara K, Bandorf N, Born J, Schultes B. Sleep loss alters basal metabolic hormone secretion and modulates the dynamic counterregulatory response to hypoglycemia. J Clin Endocrinol Metab 2007;92:3044-3051. https://doi.org/10.1210/jc.20062788.

31. Elliott R, McKinley S, Cistulli P, Fien M. Characterisation of sleep in intensive care using 24-hour polysomnography: an observational study. Crit Care 2013;17:R46. https://doi.org/10.1186/cc12565.

32. Fadayomi AB, Ibala R, Bilotta F, Westover MB, Akeju O. A systematic review and meta-analysis examining the impact of sleep disturbance on postoperative delirium. Crit Care Med 2018;46:e1204-e1212. https:// doi.org/10.1097/CCM.0000000000003400.

33. Pisani MA, D’Ambrosio C. Sleep and delirium in adults who are critically ill: a contemporary review. Chest 2020;157:977-984. https://doi. org/10.1016/j.chest.2019.12.003.

34. Knauert MP, Gilmore EJ, Murphy TE, et al. Association between death and loss of stage N2 sleep features among critically ill patients with delirium. J Crit Care 2018;48:124-129. https://doi.org/10.1016/j.jcrc.2018. 08.028 .

35. Kamdar BB, King LM, Collop NA, et al. The effect of a quality improvement intervention on perceived sleep quality and cognition in a medical ICU. Crit Care Med 2013;41:800-809. https://doi.org/10.1097/ CCM.0b013e3182746442. 
36. Preston BT, Capellini I, McNamara P, Barton RA, Nunn CL. Parasite resistance and the adaptive significance of sleep. BMC Evol Biol 2009; 9:7. https://doi.org/10.1186/1471-2148-9-7.

37. Dimitrov S, Lange T, Nohroudi K, Born J. Number and function of circulating human antigen presenting cells regulated by sleep. Sleep 2007;30:401-411. https://doi.org/10.1093/sleep/30.4.401.

38. Ibarra-Coronado EG, Pantaleón-Martínez AM, Velazquéz-Moctezuma J, et al. The bidirectional relationship between sleep and immunity against infections. J Immunol Res 2015;2015:678164. https://doi.org/ $10.1155 / 2015 / 678164$.

39. Lee H, Mizrahi MA, Hartings JA, et al. Continuous electroencephalography after moderate to severe traumatic brain injury. Crit Care Med 2019;47:574-582. https://doi.org/10.1097/CCM.0000000000003639.

40. Purandare M, Ehlert AN, Vaitkevicius H, Dworetzky BA, Lee JW. The role of cEEG as a predictor of patient outcome and survival in patients with intraparenchymal hemorrhages. Seizure 2018;61:122-127. https:// doi.org/10.1016/j.seizure.2018.08.014.

41. Hocker S, Anderson HL, McMahon KE, Wijdicks EF. Do survivors of acute neurologic injury remember their stay in the neuroscience intensive care unit? Neurocrit Care 2013;18:313-317. https://doi.org/10.1007/ s12028-013-9833-2.

42. Schwab KE, Ronish B, Needham DM, To AQ, Martin JL, Kamdar BB. Actigraphy to evaluate sleep in the intensive care unit. A systematic review. Ann Am Thorac Soc 2018;15:1075-1082. https://doi.org/10.1513/ AnnalsATS.201801-004OC.

43. Foreman B, Westwood AJ, Claassen J, Bazil CW. Sleep in the neurological intensive care unit: feasibility of quantifying sleep after melatonin supplementation with environmental light and noise reduction. J Clin Neurophysiol 2015;32:66-74. https://doi.org/10.1097/WNP.0000000000000110.
44. Huang HW, Zheng BL, Jiang L, et al. Effect of oral melatonin and wearing earplugs and eye masks on nocturnal sleep in healthy subjects in a simulated intensive care unit environment: which might be a more promising strategy for ICU sleep deprivation? Crit Care 2015;19:124. https://doi.org/10.1186/s13054-015-0842-8.

45. Vethe D, Scott J, Engstrøm M, et al. The evening light environment in hospitals can be designed to produce less disruptive effects on the circadian system and improve sleep. Sleep 2021;44:zsaa194. https://doi. org/10.1093/sleep/zsaa194.

46. Van Rompaey B, Elseviers MM, Van Drom W, Fromont V, Jorens PG. The effect of earplugs during the night on the onset of delirium and sleep perception: a randomized controlled trial in intensive care patients. Crit Care 2012;16:R73. https://doi.org/10.1186/cc11330.

47. Le Guen M, Nicolas-Robin A, Lebard C, Arnulf I, Langeron O. Earplugs and eye masks vs routine care prevent sleep impairment in postanaesthesia care unit: a randomized study. Br J Anaesth 2014;112:8995. https://doi.org/10.1093/bja/aet304.

48. Bellapart J, Appadurai V, Lassig-Smith M, Stuart J, Zappala C, Boots R. Effect of exogenous melatonin administration in critically ill patients on delirium and sleep: a randomized controlled trial. Crit Care Res Pract 2020;2020:3951828. https://doi.org/10.1155/2020/3951828.

49. Alexopoulou C, Kondili E, Diamantaki E, et al. Effects of dexmedetomidine on sleep quality in critically ill patients: a pilot study. Anesthesiology 2014;121:801-807. https://doi.org/10.1097/ALN.0000000000000361.

50. Oto J, Yamamoto K, Koike S, Onodera M, Imanaka H, Nishimura M. Sleep quality of mechanically ventilated patients sedated with dexmedetomidine. Intensive Care Med 2012;38:1982-1989. https://doi.org/ 10.1007/s00134-012-2685-y. 